\title{
Morphometric Parameters and Sex Determination of Clavicle In Telangana Region
}

\author{
*Dr Ashish Kamdi ${ }^{1}$, Dr Gayatri ${ }^{2}$, Dr Anil R. Sherke ${ }^{3}$, Dr M. Krishnaiah ${ }^{4}$, \\ Mr K.Chaitanya 5 . \\ ${ }_{1,2,3,4,5}$ Department of Anatomy, Kamineni Institute Of Medical Sciences, Narketpally.
}

\begin{abstract}
:
Background and Objectives: To determine sex from unknown skeletal remains is vital. Various methods to do this on different bones of human skeleton have been extensively studied. In general male bones are heavier, larger and muscular markings are more prominently seen as compared to female bones. The objective of this study was to find out comparative differences between the right and left clavicles from certain metrical parameters and to enable assessment of sex from unknown clavicles.

Materials \& Method: Study was conducted with 40 clavicles (right 17 and left 23) of unknown sex from the Department of Anatomy, Kamineni Institute of Medical Sciences, Narketpally. The study was an observational, cross-sectional and descriptive in nature. The maximum length of the clavicle (in mm) was taken.

Results: The length of the left clavicles varies from $123 \mathrm{~mm}$ tol64 mm with an average of $137.83 \mathrm{~mm}$ $\pm 7.99 \mathrm{~mm}$ S.D. The length of the right clavicles varies from $126 \mathrm{~mm}$ to $162 \mathrm{~mm}$ with an average $138.71 \mathrm{~mm} \pm 8.66 \mathrm{~m}$ S.D. It has been observed that the right clavicle was longer than the left clavicle by $0.88 \mathrm{~mm}$. There was no such single character which can determine the sex of all clavicles. Depending on the length alone, the sex can be decided in $0 \%$ male and $0 \%$ female right clavicles and $4.35 \%$ male and $0 \%$ female bones if the left clavicle is considered.

Conclusion: The right clavicle was longer than the left clavicle. The determination of sex from the clavicle has a great medico legal significance to the toxicologists. It also helps the anthropologists in their study of evolution of mankind and migration of races. This study is also useful for medico legal and anthropological examination of bones and for academic studies in anatomy.
\end{abstract}

Key Words: Clavicle, Demarking points, Sex determination, Vernier calliper.

\section{Introduction}

Determination of sex from unidentified human skeletal remains is a challenge for anthropologists and forensic investigators. Skeleton plays a significant role in various sciences like medicine, forensic sciences, anthropology. Estimation of sex, age, race, stature by skeleton and the presence of disease is discovered by Krogman and Iscan ${ }^{1}$. They stated that record of organic evolution is largely written by the hard parts of the body recognizable even after many years after death. Skull and pelvis ${ }^{2}$ are widely used for sex identification. Physical anthropologists and forensic pathologists have given utmost importance to the methods of stature estimation from long bones. The determination of sex by using whole skeleton or bony remnants had been explored by many workers since more than a century and individual bones including clavicle, may help at least in part if not whole, in this regard. The female clavicle is shorter, thinner, less curved and smoother and its acromial end is carried lower than the sternal end in comparison with the male. In males the acromial end is on a level with or slightly higher than the sternal end when the arm is pendant. Mid-shaft circumference of clavicle is the most reliable indicator of sex; a combination of this measurement with weight and length yields better results ${ }^{3}$.The purpose of this study was to find out an easy formula for determination of sex from unknown clavicles and to know about comparative differences between the right and left clavicles from length of clavicles. The knowledge of morphometric values is helpful to anthropological and forensic practice.

\section{Material \& Method}

40 clavicles (left 23 and right 17)from department of anatomy, Kamineni Institute of Medical Sciences, Narketpally were used for the study. Clavicles of unknown sex were used for this study. Vernier calliper was used to carry out readings. All readings were taken 3 times by same person to prevent inter-observer error. Samples with pathological changes were excluded. The maximum length of the clavicle in $\mathrm{mm}$ was taken. The length of the clavicle which was the maximum distance between two ends of the clavicle was measured with the help of a vernier calliper ${ }^{4}$. The midpoints at the acromial and sternal ends were obtained and were marked as points ' $A$ ' and ' $\mathrm{B}$ ' and were joined by straight line 'AB' as shown in figure. The data were entered in Microsoft office 2007 Excel worksheet. Then the analysis was done to derive mean and standard deviation on right and left 
sides separately. Significance of difference between mean length of right and left clavicles was tested by students ' $\mathrm{t}$ ' test. ' $\mathrm{P}$ ' value of less than 0.05 was considered as significant. Demarking points (D.P.) ) $^{5}$ were worked out from the calculated ranges (Mean $\pm 3 \mathrm{SD}$ ) and percentages of clavicles identified beyond D.P. were noted.

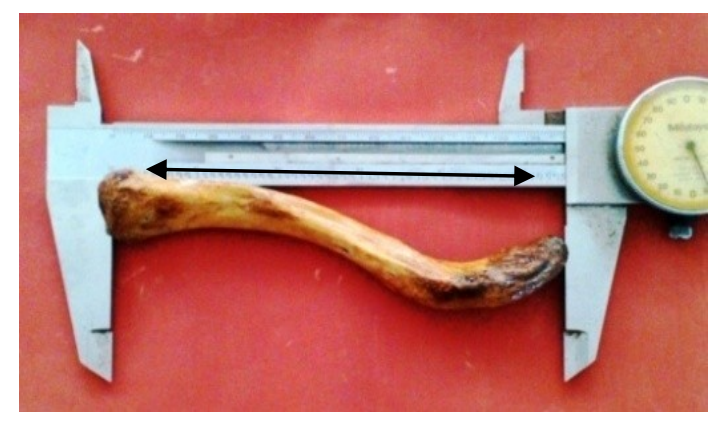

III. Results

Table: 1 Statistical measurements of the length of clavicles $(n=40)$

\begin{tabular}{|c|c|c|}
\hline Measurements & Right & Left \\
\hline Numbers & 17 & 23 \\
\hline Range & $126-162 \mathrm{~mm}$ & $123-164 \mathrm{~mm}$ \\
\hline Mean & 138.71 & 137.83 \\
\hline SD & 8.66 & $113.86-161.8$ \\
\hline Mean \pm SD (Range) & $112.73-164.69$ & Male $=>161.8$ Female $=<113.86$ \\
\hline Demarking points (D.P.) & Male $=>164.69$ Female $=<112.73$ & Male $=4.35 \%$ Female $=0 \%$ \\
\hline \% clavicles beyond D.P. & Male $=0 \%$ Female $=0 \%$ & 't' value $=0.332$ \\
\hline 'P' value $>0.05$ & \multicolumn{2}{|c|}{} \\
\hline
\end{tabular}

All the measurements are in $\mathrm{mm}$.

\section{Length of clavicles}

The length of the left clavicles varies from $123 \mathrm{~mm}$ to164 mm with an average $137.83 \mathrm{~mm} \pm 7.99 \mathrm{~mm}$ S.D. The length of the right clavicles varies from $126 \mathrm{~mm}$ to $162 \mathrm{~mm}$ with an average of $138.71 \mathrm{~mm} \pm 8.66 \mathrm{~mm}$ S.D (table 1). It has been observed that the right clavicle was longer than the left clavicle by $0.88 \mathrm{~mm}$. Although the length of the right clavicles to be marginally more than that to the left clavicles, the differences were statistically insignificant $(\mathrm{p}=0.075)$. However, in a normal distribution, the maximum and the minimum limits can be safely calculated by the formula (mean \pm 3 S.D.) by Jit I et al where mean +3 S.D. gives the maximum value and mean-3 S.D. gives the minimum value. This range includes $99.75 \%$ of the sample. Assuming that measurements on clavicles are all distributed normally, the maximum and minimum values of the measurements on clavicles for both males and females can be fixed separately. From calculations of mean and mean \pm 3 S.D., it is noticed that the maximum and minimum points of the range of males are higher than the maximum and minimum points of the range for females. Thus, it can be statistically fixed, a measurement above which no female clavicles can be found and another measurement below which no male clavicles can be seen. This measurement can be termed as the demarking points.

\section{Left clavicle}

The length of the left clavicles varies from $123 \mathrm{~mm}$ to $164 \mathrm{~mm}$ with an average $137.83 \mathrm{~mm} \pm 7.99 \mathrm{~mm}$ S.D. On the basis of this criteria (Demarking point $=$ mean \pm 3 S.D. $)^{5}$, the range was from $161.8 \mathrm{~mm}$ to 113.86 $\mathrm{mm}$. Therefore, a left clavicle having length of more than this figure $(161.8 \mathrm{~mm})$ should be considered as male. Only 1 out of $23(4.35 \%)$ left clavicles of the present series having more than $161.8 \mathrm{~mm}$ can be considered as definitely male. Similarly, a left clavicle having length of less than $113.86 \mathrm{~mm}$ can be considered as female. Zero out of $23(0 \%)$ left clavicles of the present series having less than $113.86 \mathrm{~mm}$ can be considered as definitely female. Sexing is not possible, if the lengths of the clavicles are between $113.86 \mathrm{~mm}$ and $161.8 \mathrm{~mm}$

\section{Right clavicle}

The length of the right clavicles varies from $126 \mathrm{~mm}$ to $162 \mathrm{~mm}$ with the mean of $138.71 \mathrm{~mm} \pm 8.66$ $\mathrm{mm}$ S.D. On the basis of this criteria (Demarking points = mean $\pm 3 \mathrm{SD}$ ), the range was $112.73-164.69 \mathrm{~mm}$. Therefore, a right clavicle having length of more than $164.69 \mathrm{~mm}$ should be considered as male. Zero out of 17 $(0 \%)$ right clavicles of the present series with length more than $164.69 \mathrm{~mm}$ can be considered as definitely male. Similarly, a right clavicle having length of less than $112.73 \mathrm{~mm}$ can be female. Zero out of $17(0 \%)$ right clavicles of the present series with length less than $112.73 \mathrm{~mm}$ can be considered as definitely female. If the lengths of the clavicles are between $112.73 \mathrm{~mm}$ and $164.69 \mathrm{~mm}$; sexing on this basis is not possible. 


\section{Discussion}

Male skeleton is considered to be longer and more robust than the average female, the magnitude differs from population to population. This difference can be attributed to genetic factors, environmental factors affecting growth and development like nutrition, physical activity. The measurement of long bones carry additional advantage because of its tubular nature and it can be better preserved than short bones. Differences in long bones is that typically male bones are longer and more massive than typically female bones $\left(\operatorname{krogman}^{6}\right)$. In the present study, emphasis has been put to determine the sex of unknown clavicles and to know about comparative differences between right and left clavicles from the length of clavicles.

\section{Length of Clavicle}

In the present study the mean length of right clavicles was $138.71 \pm 8.66 \mathrm{~mm}$ and that of left clavicles was $137.83 \pm 7.99 \mathrm{~mm}$. Though the mean length of right clavicle was slightly more, it was statistically insignificant. The mean values of length of clavicles were compared with the values of other studied as shown in Table 2 and 3. While doing comparison of the work of other authors regarding the mean length of clavicle, it is seen that the length of clavicle was not the same in different population and races. In the present study the mean length of right clavicle was $138.71 \pm 8.66 \mathrm{~mm}$ which was less than the mean length of right clavicles in France $(146.05 \mathrm{~mm})^{7}$, U.S.A. Negros study done by Terry RJ $(147.14 \pm 0.79 \mathrm{~mm})^{8}$, U.S.A. Whites study done by Terry RJ $(152.90 \pm 0.88 \mathrm{~mm})^{8}$, England $(145 \mathrm{~mm})^{9}$, and U.S.A. Negros study done by Singh S $(146.66 \mathrm{~mm})^{10}$. Therefore the right clavicle of Telangana population was shorter than the above population.

Table: 2: Comparison of mean values of the length of clavicles in different countries

\begin{tabular}{|c|c|c|}
\hline \multirow{2}{*}{ Population } & \multicolumn{2}{|c|}{ Mean length of clavicles in mm } \\
\cline { 2 - 3 } & Right & Left \\
\hline French (Olivier G) & 146.05 & 146.85 \\
\hline U.S.A. Negros (Terry RJ) & $147.14 \pm 0.79$ & $148.82 \pm 0.47$ \\
\hline U.S.A. Whites (Terry RJ) & $152.90 \pm 0.88$ & $154.10 \pm 0.91$ \\
\hline English (Parsons FG) & 145 & 146.50 \\
\hline U.S.A. Negros (Singh S) & 146.66 & 149.06 \\
\hline U.S.A. Whites (Singh S) & 142.54 & 144.10 \\
\hline Nepal (Haque MK et al) & $143.21 \pm 11.13$ & $145.53 \pm 11.04$ \\
\hline Present Study & $138.71 \pm 8.66$ & $137.83 \pm 7.99$ \\
\hline
\end{tabular}

In the present study the mean length of left clavicle was $137.83 \pm 7.99 \mathrm{~mm}$ which was less than the mean length of left clavicles in France $(146.85 \mathrm{~mm})^{7}$, U.S.A. Negros study done by Terry RJ $(148.82 \pm 0.47 \mathrm{~mm})^{8}$, U.S.A. Whites study done by Terry RJ $(154.10 \pm 0.91 \mathrm{~mm})^{8}$, England $(146.50 \mathrm{~mm})^{9}$ and U.S.A. Negros study done by Singh $S(149.06)^{10}$. Therefore the left clavicle of Telangana population was shorter than the above population. There was a very little difference in Mean values of length of right and left clavicles of U.S.A. Whites study done by Singh $\mathrm{S}^{10}$, Nepalese population study done by Haque et $\mathrm{al}^{4}$ and present study. (Table: 2 ). It is apparent from the Table: 3 that the mean values of the length of clavicles in Varanasi zone study done by Singh et $\mathrm{al}^{11}$ was less than the present study both for right and left sides. The mean values of the length of clavicles in Chandigarh Zone study done by Jit I et $\mathrm{al}^{12}$ and Chandigarh zone study done by Kaur $\mathrm{H}$ et $\mathrm{al}^{13}$ and Gujarati population done by Hiren S. Chavda et $\mathrm{al}^{16}$ were more than the present study both for right and left sides. Study done in Amritsar zone by Jit et $\mathrm{al}^{5}$, length of clavicle was less on right side and more on left side when compared with present study. Findings of present study supported the finding of study of Varanasi zone $\left(\right.$ Singh et al) ${ }^{11}$ that the length of right clavicle was usually longer then the left clavicle. (Table:3, Table:4).

Table: 3: Comparison of mean values of the length of clavicles in different zones of India

\begin{tabular}{|c|c|c|}
\hline \multirow{2}{*}{ Population } & \multicolumn{2}{|c|}{ Mean length of clavicles in mm } \\
\cline { 2 - 3 } & Right & Left \\
\hline Varanasi zone (Singh et al) & $138.63 \pm 7.85$ & $135.97 \pm 8.05$ \\
\hline Amritsor zone (Jit et al) & $137.97 \pm 8.85$ & $138.69 \pm 5.51$ \\
\hline $\begin{array}{c}\text { Chandigarh zone (Jit I et al) } \\
\text { H et al) }\end{array}$ (Kaur & $140.20 \pm 8.50$ & $141.90 \pm 8.25$ \\
\hline $\begin{array}{c}\text { Chandigarh zone population } \\
\text { Chavda et al ) }\end{array}$ & $141.96 \pm 9.29$ & $143.67 \pm 9.18$ \\
\hline $\begin{array}{c}\text { Present Study S. } \\
\text { Region) }\end{array}$ & $142.28 \pm 11.40$ & $145.14 \pm 11.87$ \\
\hline
\end{tabular}

\section{Determination of Sex:}

The female clavicle is shorter, thinner, less curved and smoother in comparison with male clavicle. In present study, an attempt has been done to assess sex from unknown clavicles by length of clavicles. In a normal distribution, the maximum and minimum limits can be safely calculated by the formula MEAN \pm 3 S.D. by Jit et al where mean+3S.D. gives the maximum value and mean-3S.D. gives the minimum value. This range includes 
$99.75 \%$ of the sample ${ }^{5}$. Assuming that the measurements on clavicles are all distributed normally, the maximum and minimum values of the measurements on clavicles for both males and females separately can be fixed. It is apparent from the table: 1 that we got a measurement above which no female clavicles can be found and another measurement below which no male clavicles can be seen. These measurements are termed as demarking points ${ }^{4}$. As seen from table: 1 that on right side mean \pm 3 S.D. range for length of clavicle is $112.73-164.69 \mathrm{~mm}$ and on left side this range is 113.86-161.8 $\mathrm{mm}$. On the basis of criteria of demarking points, a right clavicle having length of more than $164.69 \mathrm{~mm}$ should be considered as male. Zero out of $17(0 \%)$ right clavicles of present study with length more than $164.69 \mathrm{~mm}$ can be considered as definitely male. Right clavicle having length less than $112.73 \mathrm{~mm}$ can be female. Zero out of $17(0 \%)$ can be considered as females. Sexing is not possible, If the lengths of the clavicles are between $112.73 \mathrm{~mm}$ and $164.69 \mathrm{~mm}$. As seen from table: 1 that on left side on the basis of this criteria (Demarking Point= Mean $\pm 3 \mathrm{SD}$ ), the range was113.86-161.8 $\mathrm{mm}$. Therefore, a left clavicle having length of more than $161.8 \mathrm{~mm}$ should be considered as male. Only 1 out of $23(4.35 \%)$ left clavicles of the present study with length more than $161.8 \mathrm{~mm}$ can be considered as definitely male. Left clavicle having length less than $113.86 \mathrm{~mm}$ can be female. Zero out of 23 clavicles $(0 \%)$ can be considered as females. Sexing is not possible, if the lengths of the clavicles are between $113.86 \mathrm{~mm}$ and $161.8 \mathrm{~mm}$. Table:4 shows that in the present study only $0 \%$ male clavicles and $0 \%$ female clavicles can be found out from right clavicles and only $4.35 \%$ male clavicles and $0 \%$ female clavicles can be found out from left clavicles. Sexing was not possible in $100 \%$ right clavicles and $95.65 \%$ left clavicles.

Table:4 Comparison of percentage of clavicles identified as males and females by Demarking points in different studies

\begin{tabular}{|c|c|c|c|c|}
\hline \multirow{2}{*}{} & \multicolumn{2}{|c|}{ Right } & Left & \\
\cline { 2 - 5 } & Male & Female & Male & Female \\
\hline Kaur K et al & $18 \%$ & $3 \%$ & $19 \%$ & $3 \%$ \\
\hline Jit I et al & $8.3 \%$ & $13.7 \%$ & $19.8 \%$ & $11.5 \%$ \\
\hline Haque MK et al & $13.33 \%$ & $4.44 \%$ & $16.39 \%$ & $9.83 \%$ \\
\hline Hiren S. Chavda et al & $3.13 \%$ & $2.08 \%$ & $1.71 \%$ & $1.71 \%$ \\
\hline Present Study & $0 \%$ & $0 \%$ & $4.35 \%$ & $0 \%$ \\
\hline
\end{tabular}

As seen from table:4 that in the present study, sex can be identified from very few percentages of clavicles on both the sides compared to study by Kaur K et $\mathrm{al}^{14}$, $\mathrm{Jit}_{\mathrm{et}} \mathrm{al}^{5}$, and Haque MK et $\mathrm{al}^{15}$ and Hiren S. Chavda et $\mathrm{al}^{16}$.

\section{Summary And Conslusion}

40 clavicles of unknown sex were collected from department of anatomy, Kamineni Institute of Medical Sciences, Narketpally. By eliminating pathologically misfit clavicles, 40 clavicles in good condition were selected. Each clavicle was carefully measured for the parameters which are already described in materials and methods. The measurements were statistically analyzed and tabulated. The measurements were compared to the values available in reference material. Every parameter is independent of others and contribute certain percentage of certainty to decide the sex of unknown clavicle. From the present study it can be concluded that, the right clavicle was longer than the left clavicle. There are many characters from which we can determine the sex of an individual. In present study, depending upon the length of clavicle the sex can be determined in $0 \%$ male and $0 \%$ female from right clavicles and $4.35 \%$ male and $0 \%$ female from left clavicles. The determination of sex from the clavicle has a great medico legal significance to the toxicologists. It also helps the anthropologists in their study of evolution of mankind and migration of races. The knowledge of morphometric values is helpful to anthropological and forensic practice.

\section{Acknowledgments}

The authors acknowledge great help received from the authors / editors / publishers of all those articles, journals and books from where the literature for this article has been reviewed and discussed. We also acknowledge great help received from the scholars whose articles cited and included in references of this manuscript.

\section{References}

[1]. Krogman, W. M. and Iscan, M. Y. Human Skeleton in Forensic Medicine. 2nd Edition, Charles C. Thomas, Springfield, 1986.

[2]. Asala . S.A. et al 2004 Discriminant function sexing of fragmentary femur of South African blacks, vol 145, issue 1. p. 25-29

[3]. Standring Susan. Gray's anatomy, the anatomical basis of clinical practice, 40th edi. Churchill Livingstone,Elsevier, 2008, p. 791792

[4]. Haque MK et al. Morphometric analysis of clavicle in Nepalese population. Kathmandu univ Med J. 2011; 35(3):193-197

[5]. Jit I, Singh S. The sexing of adult clavicles, Indian journal of medical research. 1966; 54:551-571

[6]. Krogman, W. M. and Iscan, M. Y. Human Skeleton in Forensic Medicine. 2nd Edition, Charles C. Thomas, Springfield, 1986.

[7]. Olivier G. Anthropologie de la Clavicule.III,La Clavicule due francis. Bulltins et. Memories de la societe. D' Anthropologie 1951;2:121-157 
[8]. Terry RJ. The clavicle of the American Negro. Americal journal of physical anthropology.1932;16:351-380

[9]. Parsons FG. On the proportions and characteristics of the modern English clavicle. Journal of Anatomy .1916:51:7193

[10]. Singh S. Sexing of American clavicles. Journal of anatomical society of India. 1969;18:25 (abstract)

[11]. Singh S,Gangrade K.C. The sexing of adult clavicles-demarking points for varanasi zone. Journal of anatomical society of India.1968b;17:89-100

[12]. Jit I, Sahni D. Sexing of North Indian clavicles. Journal of anatomical society of India.1983;32(2):61-72

[13]. Kaur H, SahniD, Jit I. Length \& curves of the clavicle in northwest Indian.Journal of Anatomical society of India.2002;(51)2:199209

[14]. Kaur K,Sidhu S S,kaushal S,Kaur B. Sexing of the North west Indian adult clavicles of patiala zone. Journal of anatomical society of India. 1997;48(2):121-130

[15]. Haque MK et al. Study of curvatures of clavicle with its clinical importance. Kathmandu univ Med J. 2011; 36(4):279-282

[16]. Hiren S. Chavda et al. Morphometric analysis of clavicles in Gujarat. NJIRM 2013; Vol. 4(6):18-22 